\title{
Realización apropiada de la linfadeno-histerectomía amplia
}

\author{
POR EL DOCTOR CONRAdO ZUCKERMANN \\ Director del Instituto de Cancerología de Méjico. - Profesor de Ginecologia \\ de la Facultad de Medicina de Méjico.
}

\section{PRELIMINAR:}

Ciertamente que uno de los argumentos empleados en contra de la cirugía extirpadora del cáncer del cuello uterino, es que su ejecución no cumple con frecuencia con las normas clásicas señaladas para la cirugía anticancerosa, que afirma que en los blastomas epiteliales debe extirparse casi siempre el tumor original junto (en un solo bloque) con los ganglios linfáticos inmediatos correspondientes y además que es mejor hacerlo de la probable metástasis al seguro cáncer, es decir, de afuera - lo más afuera posible- hacia adentro, sin tocar el tejido canceroso.

La diseminación y multiplicidad de los ganglios linfáticos pélvicos correspondientes al cervix uterino, la fiabilidad de ios tejidos existentes entre el cáncer cervical y los ganglios metastasiados y el hecho de pasar en esa zona un órgano de gran importancia, el uretere, hacen difícil cumplir con los postulados.

A pesar de ello, la extirpación quirúrgica tiene sus indudables triunfos debidos a dos circunstancias: a que el cáncer todavía no invada las zonas linfáticas, es decir, a que esté en período I o II o que estando ya en etapa III la propagación cancerosa no se realizó por invasión célula a célula, es decir, por canalitos linfáticos ocupados por ellas, sino por embolización (traslado) y entonces la sección entre el tumor original y el ganglio a pesar de no ser correcta, no perjudica.

Consideramos que es posible procurar hacer la extirpación en un solo bloque que comprenda los ganglios pélvicos correspondientes y el tejido conjuntivo-grasoso que les rodea, los anexos, 
parametrios, paracervix y paracolpos, el tercio superior o más de la vagina y la matriz cancerosa.

Los ganglios linfáticos correspondientes son: los ilíacos primitivos, sacros laterales, ilíacos externos y obturatrices, ilíacos internos y los paracervicales.

Los paracervicales o yuxtacervicales son extirpados podemos decir siempre, desde que se realizan las clásicas operaciones de WERTHEIM o la de LATZKO.

Los ganglios más importantes de extirpar son los obturatrices e ilíacos externos y los ilíacos internos, pues los exámenes histológicos demuestran que son los más frecuentemente atacados.

Las técnicas operatorias más conocidas no toman en cuenta que los pedículos linfáticos principales son dos: el preureteral que es indudablemente el mayor y que comprende los canalitos linfáticos que van a los ganglios obturatrices e ilíacos externos y parte de los ilíacos internos y el pediculo intraureteral (o retroureteral) que desemboca en los ganglios ilíacos internos y en los sacros laterales y que es mucho menor que el anterior.

Precisamente esta disposición del ureter pasando entre los pedículos linfáticos y el hecho de la friabilidad del tejido periganglionar y pericanalicular linfático es lo que dificulta la extirpación en un solo bloque.

\section{TECNICA Y TACTICA}

Para intentar realizar y cumplir lo más posible las reglas de la cirugía oncológica, procedemos en la actualidad de la manera siguiente: seccionamos el peritoneo pélvico de una ilíaca primitiva a otra, dejando el uretere unido a la hoja serosa interna. Ligamos y seccionamos los ligamentos infundíbulo-ovárico y redondo de cada lado. Tomamos el peritoneo de adentro con pinzas, llevando el uretere hacia adentro y procedemos con tijera curva sin punta, pinzas o con disector, a separar el tejido conjuntivo-grasoso colocado adentro de las ilíacas primitivas (ganglios sacros laterales), encima, afuera y atrás de ellas (ganglios ilíacos primitivos) y siguiendo de atrás hacia adelante y de afuera hacia adentro, continuamos la separación-disección, levantando el tejido conjuntivo-graso-linfático que rodea a la ilíaca externa (gangịos ilíacos externos y obturatrices); a continuación hacemos 10 mismo alrededor de los vasos ilíacos internos (ganglios iliacos internos); durante todas estas maniobras el uretere está hacia adentro. En la zona obturatriz no solamente debe quedar bien visible 
el nervio obturador sino vacía la foseta y ligada toda vena que sangre; la disección al nivel de esta fosa debe ser extremadamente cuidadosa, pues las heridas arteriales o venosas en esta zona son difíciles de cohibir o por lo menos muy molestas.

Ya teniendo en una gran masa el conjuntivo-grasoso-linfático ilíaco-obturatriz y previa sección del peritoneo vésico-uterino, separamos hacia abajo la vejiga haciéndolo con tijeras y pinzas o con torunda de gasa y realizándolo en suficiente extensión; en caso de abrirse la vejiga ésta puede suturarse desde luego o realizarlo una vez terminada la gran extirpación.

Se secciona entre pinzas y se liga el conducto obliterado de la arteria umbilico-vesical y se hace lo mismo con la unión de la masa conjuntivo-grasosa-linfática con las partes laterales de la vejiga; esta separación de dicha masa conjuntivo-grasoso-linfática de la vejiga, es importante, pues hemos observado que el no hacerlo puede traer el que se dejen ganglios cancerizados en dicha zona a uno u otro lado de la vejiga.

En seguida se levanta lo separado, la masa conjuntivo-grasosa linfática colocándola adelante de la zona cervical del útero por extirpar.

La ligadura de la uterina o de la ilíaca interna se realiza fácilmente, pues la disección-extirpación linfática las deja bien visibles y entre dos pinzas su sección es fácil, debiendo ligarse inmediatamente el cabo externo, mientras que el interno - hacia el útero - se deja tomado con la pinza, lo que colabora al apropiado levantamiento-separación del conjuntivo-grasoso-linfático que se trata de extirpar junto con la matriz y anexos.

Se procede después a la disección-separación ureteral, que debe ser realizada sobre todo en los tres centímetros últimos de su desembocadura en la vejiga; es el tiempo principal de la operación y sólo es realizable en forma poco sangrante gracias a la ligadura de la uterina pegada a la hipogástrica, o a la ligadura de la propia hipogástrica. Las maniobras alrededor del uretere deben ser cuidadosas, bien visibles y todo corte hecho por el lado externo de estco zona ureteral y no por adelante para evitar seccionar el pedículo linfático principal, que como hemos señalado, es preureteral.

Insistimos en que la disección-separación del uretere debe realizarse llevando toda la masa conjuntiva-grasosa-linfática hacia adelante y adentro y en cambio el uretere hacia atrás y afuera y haciendo las secciones que amerite por fuera del uretere hasta 
lograr que éste quede bien afuera y que se observe limpia e intacta su entrada a la vejiga.

Terminada la separación ureteral y vesical y alejados dichos órganos, se procede a la sección de los ligamentos útero-sacros viendo bien a los ureteres (como precaución); se liga desde luego el corte de sección de los ligamentos útero-sacros y se separa la cara anterior del recto de la vagina.

Una vez realizada la sección-separación que acabamos de anotar, se observa que toda la masa de extirpación (linfáticosanexos-útero asciende, se asegura que el alejamiento de ureteres, vejiga y recto es suficiente, y se toma con pinzas, una para cada lado, el paracolpos y después se colocan las pinzas acodaclas de Wertheim y tomando los extremos externos de la vagina (lo que no siempre es posible) se procede a la sección de ésta, utilizando para ello tijeras largas de punta roma muy curva.

La extirpación está terminada.

Se ligan los pedículos del paracolpos y se sutura (en caso posible) con una puntada el borde externo del corte vaginal.

Se revisa toda la zona operatoria haciéndolo de una iliaca primitiva a la otra y poniendo atención en que no quede porción alguna tisular (ganglionar o no ganglionar) sospechosa de cancerización; además se revisa lo referente a gasas que hubieran servido para hemotasis temporal.

La conservación de la pequeña arteria ureterál nacida en la ilíaca primitiva o en la interna, señalada por algunos autores, casi siempre es bien difícil y lo que se procura es dejar el uretere hacia afuera después de haberlo separado con el mínimo posible de maniobras, de cortes y de ligaduras en su cercanía.

Se efectúa en seguida la peritonización.

\section{DETALLES COMPLEMENTARIOS}

Consideramos que la incisión vertical, del pubis hacia el ombligo subiendo casi siempre (y a la izquierda) del mismo, da campo operatorio muy suficiente siempre que se empleen los separadores apropiados, valvas laterales que den suficiente separación y valva suprapúbica mediana que no tape las zonas obturatrices. La incisión horizontal, seccionando los rectos anteriores, da también buen campo, pero su realización y el cierre y reconstrucción ocupa nı́s tiempo, debiéndose tomar en cuenta que la mayor cantidad de tiempo debe dedicarse a la linfadenectomía y no a maniobras o procedimientos no necesarios. 
La linfadenectomía debe hacerse como antes hemos dicho con ei uretere hacia adentro y lo más completa posible, iniciándose atrás en la ilíaca primitiva a la altura del promontorio y llevándola abajo y afuera hasta el final de la arteria ilíaca externa, pero sin pretender meterse a la región inguinal lo que casi siempre es innecesario. El levantar con pinzas o cinta la arteria iliaca externa puede ser útil y ello permite evitar que queden ganglios colocados entre ella y la vena o entre ella y el músculo psoas. La disección de la ilíaca interna y la separación de ella del tejido conjuntivo-grasoso-linfático, debe ser igualmente minuciosa y a su seguimiento es útil ligar la uterina en su nacimiento en la hipogástrica o el tronco común de la uterina y vaginal (y a veces una vesical) que se observa claramente. En algunas ocasiones puede ser útil ligar directamente la hipogástrica, sobre todo si se observa hemorragia intensa a ia disección.

Consideramos que la incisión vertical dei pubis hacia el omsobre la ilíaca interna y en el territorio de la región obturatriz. Esto lo afirmamos porque hemos visto operaciones en que la disección y limpia peri-iliaca primitiva y externa ha siajo pudiéramos decir completa, pero en cambio adentro de la ilíaca externa, en la zona obturatriz y en la ilíaca interna la limpia ha sido demasiado incompleta.

La separación conjuntivo-grasosa-ganglionar-linfática, debe ser lo más completa posible y una vez realizada es muy de señalarse que toda la masa de tejido así obtenida debe ser separada cle la parte lateral de la vejiga; el no hacerlo trae - como hemos visto- dejar parte de dicha masa (y por lo tanto ganglios linfáticos) ; para realizarlo debe ligarse y seccionarse el conducto obliterado de la arteria umbilico-vesical y poner otra ligadura en el límite con la vejiga que ha sido bien identificada y separada hacia adentro y abajo.

\section{RESUMEN}

1. Es necesario procurar cumplir, en la extirpación del cáncer cérvico-uterino, con lo señalado en las reglas de la cirugía cancerológica que indican hacerlo en un solo bloque ganglionar!infático-uterino-anexial.

2. Es bastante difícil, pero no imposible, realizar la extirpación en un solo bloque y al efectuarlo debe recordarse que el pedículo linfático principal es preureteral. 
3. La linfadenectomía debe preceder a la histerectomía amplia efectuada en continuidad anatómica con la extirpación linfático-ganglionar.

4. La extirpación ganglionar obturatriz-ilíaca y a los lados de la vejiga debe ser completa y para lograrlo es apropiado seccionar y ligar el conducto obliterado de la arteria umbilico-vesical.

5. El uretere debe mantenerse hacia adentro mientras se realiza la disección ilíaco-obturatriz y hacia afuera cuando se termina la extirpación utero-anexial-vaginal.

6. La separación ureteral, vesical y rectal debe ser suficiente y en caso de ocurrir herida de estas vísceras, hacerse inmediatamente la reparación conducente.

7. El paracolpos debe ser seccionado muy afuera del extremo superior de la vagina y ligado para evitar molestas hemorragias.

8. La peritonización es posible y muy útil y debe hacerse después de cuidadosa revisión de la gran superficie cruenta para evitar dejar zonas sangrantes y gasas hemostáticas.

9. La incisión vertical suprapública nos parece muy apropiada, siendo su ejecución y la reparación posterior realizadas en menos tiempo que lo referente a las incisiones horizontales amplias (las no amplias serían inadecuadas).

10. Solo las extirpaciones amplias que comprenden los gangiios linfáticos tributarios, matriz, anexos, gran porción vaginal, el paracolpos y paracervix, permiten obtener apropiados resultados.

11. La técnica-táctica de linfadeno-histerectomía descrita es propia para cáncer del cuello uterino en etapa regional pélvica y sin metástasis viscerales ni óseas. 